\title{
BMJ Global Health A guide to systems-level, participatory, theory-informed implementation research in global health
}

Nadine Seward (D) , ${ }^{1}$ Charlotte Hanlon (1) ${ }^{2,3}$ Saba Hinrichs-Kraples (1) ${ }^{4}$
Crick Lund, ${ }^{5,6}$ Jamie Murdoch (D) , ${ }^{7}$ Tatiana Taylor Salisbury, ${ }^{5}$ Ruth Verhey,
Rahul Shidhaye (i) , ${ }^{8}$ Graham Thornicroft, ${ }^{5}$ Ricardo Araya, ${ }^{5}$ Nick Sevdalis ${ }^{10}$

\section{ABSTRACT}

Hinrichs-Kraples S, et al. A guide to systems-level, participatory, theory-informed implementation research in global health. BMJ Global Health 2021;6:e005365. doi:10.1136/ bmjgh-2021-005365

Handling editor Seye Abimbola

- Additional supplemental material is published online only. To view, please visit the journal online (http://dx.doi.org/10. 1136/bmjgh-2021-005365)

$\mathrm{CH}, \mathrm{SH}-\mathrm{K}, \mathrm{CL}, \mathrm{JM}$ and TTS contributed equally.

Received 12 February 2021 Accepted 3 December 2021

\section{Check for updates}

\section{Author(s) (or their} employer(s)) 2021. Re-use permitted under CC BY-NC. No commercial re-use. See rights and permissions. Published by BMJ.

For numbered affiliations see end of article.

Correspondence to Dr Nadine Seward; nadine.seward@kcl.ac.uk
Implementation research is a multidisciplinary field that addresses the complex phenomenon of how context influences our ability to deliver evidenceinformed healthcare. There is increasing realisation of the importance of applying robust implementation research to scale-up life-saving interventions that meet health-related sustainable development goals. However, the lack of high-quality implementation research is impeding our ability to meet these targets, globally. Within implementation research, theory refers to the proposed hypothesis and/or explanation of how an intervention is expected to interact with the local context and actors to bring about change. Although there is increasing interest in applying theory to understand how and why implementation programmes work in real-world settings, global health actors still tend to favour impact evaluations conducted in controlled environments. This may, in part, be due to the relative novelty as well as methodological complexity of implementation research and the need to draw on divergent disciplines, including epidemiology, implementation science and social sciences. Because of this, implementation research is faced with a particular set of challenges about how to reconcile different ways of thinking and constructing knowledge about healthcare interventions. To help translate some of the ambiguity surrounding how divergent theoretical approaches and methods contribute to implementation research, we draw on our multidisciplinary expertise in the field, particularly in global health. We offer an overview of the different theoretical approaches and describe how they are applied to continuously select, monitor and evaluate implementation strategies throughout the different phases of implementation research. In doing so, we offer a relatively brief, user-focused guide to help global health actors implement and report on evaluation of evidencebased and scalable interventions, programmes and practices.

\section{INTRODUCTION}

In poorly resourced settings within low-income and middle-income countries (LMICs) and within some high-income countries, access to high-quality evidence-informed healthcare is
Summary box

Despite the evidence that highlights the need for im plementation research to achieve the United Nation's Sustainable Development Goals, global health researchers often do not incorporate core implementation components in their work systematically.

- This guide aims to address the lack of guidance describing how to apply a range of theoretical approaches and methods that address specific questions in the context of implementation research for global health.

- In doing so, we aim to offer a relatively brief, userfocused guide to help multidisciplinary global health groups design, implement and report on evaluation of evidence-based and scalable interventions, programmes and practices.

- Improving the quality of implementation research in global health cannot be achieved without decolonising the very structures global health is based on This includes, but is not limited to, ensuring research agendas are no longer set by donors from the global North. Instead, research should be driven by people from the South-the holders of knowledge of the local needs and priorities and the context that shapes their health systems.

severely limited. ${ }^{12}$ In these settings, a range of contextual and behavioural barriers and enablers at the macrolevel, mesolevel and microlevel, influence our ability to deliver this care including sociocultural, socioeconomic, geographical, epidemiological, psychological, ethical, legal and political determinants. Overcoming these barriers and leveraging the enablers to effectively implement evidenceinformed practice requires a mixed-methods, theoretically informed approach involving stakeholders from all levels of the health system, including service users. This is inherently different from the approach typically applied to clinical trials, which test the effectiveness of a novel drug or therapy. ${ }^{4}$ 
Implementation research is widely recognised as 'the scientific inquiry into questions concerning implementation-the act of carrying an intervention into effect, which in health research can be policies, programmes or individual practices (collectively called interventions) ${ }^{5}$. Although the terms 'implementation research' and 'implementation science' are used interchangeably in the literature, we use this definition as an umbrella term, under which fall various theoretical approaches and methods. As an example, we situate implementation science (eg, determinant frameworks, evaluation frameworks and implementation theories) as one approach within implementation research that studies the methods for how we bring evidence-informed care to scale.

In order to ensure healthcare interventions improve health outcomes, a central concern of implementation research is to develop, test and refine the theory of how delivery of the intervention can be optimised within complex social settings. Within implementation research, theory can refer to the proposed hypothesis and/or explanation of how an intervention is expected to interact with the local context and actors to bring about change. ${ }^{6-8}$ Implementation research typically requires multidisciplinarity that draws on a range of theoretical approaches. The theoretical approaches applied to implementation research arise from different knowledge paradigms that view the world differently, such as positivism (reality is a set of observable events) or critical realism (reality exists separately from social actors) or relativism (reality is subject to different interpretations of how actors engage with one another and the context). ${ }^{9}{ }^{10}$ Because of this, implementation research is faced with a particular set of challenges about how to reconcile different ways of thinking and constructing knowledge about healthcare interventions. Box 1 describes how different theoretical approaches offered by different knowledge paradigms contribute to implementation research.

These challenges are not unique to implementation research. Given that implementation research is about strengthening health systems to ensure access to and delivery of high-quality affordable care, it also shares close ties with Health System and Policy Research
(HSPR). ${ }^{5}$ Indeed, HSPR has been defined as 'a discipline that seeks to understand and improve how societies organise themselves in achieving collective health goals, and how different actors interact in the policy and implementation processes to contribute to policy outcome'. ${ }^{9}$ Due to the increased awareness of its importance for health system strengthening, implementation research is now a rapidly expanding discipline that tests, refines and adapts different strategies to address barriers and build on enablers to bring high-quality evidence-informed practice to scale. $^{5}$

Whereas public health in LMICs addresses issues relevant to a particular community or country, ${ }^{11}$ the focus of global health is the quest for equity, including within high-income countries as well as within LMICs. ${ }^{12}$ As such, global health is defined by problems of delivering high-quality evidence informed care in practice, especially to the most vulnerable. Like HSPR, implementation research is a highly interdisciplinary and multidisciplinary field that address delivery problems in global health. $^{12}$

\section{Current state of implementation research in global health}

Despite the evidence that highlights the need for implementation research to achieve the United Nations Sustainable Development Goals ${ }^{13}$ a review addressing how these approaches and methods are being applied in LMICs suggests that researchers often do not incorporate core implementation components in their work. ${ }^{14}$ As an example, the review found that only a very small number of articles made use of implementation models or theories. The review also found that of the studies that reported their research as implementation research, only $52 \% \quad(\mathrm{n}=415)$ described contextual determinants and fewer than $5 \%$ addressed objectives focused on scaling up $(n=32)$ or sustainability $(n=25)$. Box 2 describes characteristics of high-quality implementation research.

Reasons for the above weaknesses are complex and stem beyond the novelty of some of the implementation science developments or the multidisciplinary nature of the work. Much of global health research is driven by actors in the North (ie, high-income country

\section{Box 1 The contribution of theoretical approaches offered by the different knowledge paradigms to implementation research}

Positivism: Views the world as observable events that can be measured. Positivists use deductive reasoning by primarily adapting quantitative methods to test hypotheses about a proposed intervention, that is grounded in previous research or proposed theories. Positivist approaches to implementation research address questions such as 'what is the effectiveness of task-shifting in increasing access to psychological therapies?', and 'how does stigma influence the effectiveness of task-shifting in increasing coverage of psychological therapies?'.

Relativism: Views reality as subject to different interpretations, generating multiple realities that are constructed and shifting over time through the actions and interactions of different actors. ${ }^{910}$ Relativists use inductive approach that is not driven by a hypothesis to generate a theory about a phenomenon or to test a pre-existing theory. A relativist approach to implementation research address questions such as 'How do social processes influence a patient's understanding and experiences of task-shifting to improve access to psychological therapies for depression'.

Critical realism: Views reality as existing independently from social actors, stratified by social structures (eg, healthcare systems, political institutions, economies) and processes (eg, political, legal, ethical and bureaucratic policies). Critical realists use both deductive (theory testing) and inductive (theory building) approaches. By framing the social world as socially structured actions and mechanisms, critical realists produce knowledge on a range of mechanisms which mediate the relationship between cause and effect within different contexts and therefore addressing questions surrounding what works for whom and under what circumstances. ${ }^{9}$ 
Box 2 Key principles and concepts to support high-quality implementation research in low-income and middle-income countries (LMICS)

Capacity building: The need to build capacity to conduct high-quality implementation research in global health is greatest in resource-poor contexts within LMICs. Despite efforts to increase the numbers of researchers who are able to carry out high-quality research, numbers remain low. ${ }^{74}$

Context: Implementing evidence-informed practices needs to account for the context-any feature of the circumstances in which an intervention is conceived, developed, implemented and evaluated. ${ }^{75}$ With implementation research in LMICs, addressing 'contextual equipoise' is particularly relevant as it helps to ensure that implementation efforts account for the needs and priorities of the local population in addition to preventing the inappropriate use of randomised controlled trials that denies participants in the control arm access to treatments that is known to be effective within the local context. ${ }^{76}$

Evidence-informed practice: Whereas evidenced-based care is considered the gold standard for effective healthcare delivery, the application of evidence into practice is referred to as evidence-informed practice. ${ }^{77}$ This distinction is important as the application of evidence into practice encounters multiple difficulties including challenges with unstable settings with rapidly changing contexts and unintended consequences. Many healthcare practitioners therefore feel that implementing evidence-based practice, should be informed by, as opposed to based on, evidence.

Embedding research activities into existing programmes and health systems: Embedded research is carried out as an integrated and systematic part of decision making and implementation that involves the collaboration between policy-makers, implementers and communities. ${ }^{33}$ Embedding research improves ownership and, therefore, the application of the research findings.

Evaluation in real-world settings: Most implementation research in global health is conducted in resource-constrained settings. In order to bring evidence based care to scale, it is essential that implementation research is embedded in the local health system or community, allowing research to be conducted in real-world conditions, with the types of resources, incentives and operational support they would have under routine situations. ${ }^{14}$

Mixed-methods approach: Both quantitative and qualitative methods are required to understand how and why interventions work in real-world settings: Findings are then triangulated to conceptualise and confirm how the implementation of evidence-informed practice led to the measured impact. $^{1478}$

Multistakeholder involvement and engagement: Collaboration and partnerships among multiple stakeholders (such as academics, implementers, users, advocates, policy-makers and donors) across various influence domains (research, programme, policy and funding) is important for any implementation research enterprise to achieve large-scale impact. ${ }^{14}$ Ensuring involvement of stakeholders who can potentially influence implementation efforts can also help to ensure the intervention is meeting the needs and proprieties of the population it is intended on serving.

Scale-up: many effective treatments are never brought to scale which is often referred to as the 'delivery gap'. ${ }^{79}$ Applying robust implementation research, can help support scale-up. ${ }^{80}$

Systems-level approach: a systems-level approach to the design and evaluation of interventions, views a complex intervention as a system in itself, interacting with other building blocks of the underlying health system in which the intervention embeds itself, setting off reactions that may well be unexpected or unpredictable. ${ }^{81}$

Sustainability: is the extent to which a newly implemented treatment is maintained or institutionalised within a service setting. With implementation research in LMICs, sustainability is essential as it is unethical to implement evidence-informed care that has effectively improved health outcomes in other settings, only to withdraw this treatment if it is not sustainable. ${ }^{82}$

Theory-driven research: A theory can be defined as a set of analytical principles or statements designed to structure our observation, understanding and explanation of the world. ${ }^{35}$ Within the field of implementation science, this research uses theory to develop a set of propositions or hypotheses about how implementation phenomena might unfold, which are subsequently testes through collection of empirical observations.

Arguably, all attempts to improve healthcare and its outcomes are driven by theory ${ }^{83}$; theory-driven research makes such theories explicit and allows them to be tested in practice, so that an evidence-based accumulates gradually around implementation phenomena.

Unintended consequences: With implementation research there are often outcomes that are not anticipated that can be positive or negative. ${ }^{84}$ It is important to be mindful of, and explore whether any unintended or unanticipated consequences occur as a result of implementation efforts. Research projects should be designed to allow for the identification and effective management of unintended consequences. ${ }^{85}$

Health systems strengthening (HSS): involves comprehensive changes to policies and regulations, organisational structures, and relationships across the health system building blocks (eg, service delivery, health workforce, health information systems, access to essential medicines, financing and leadership/governance) that motivate changes in behaviour, and/or allow more effective use of resources across multiple care platforms. ${ }^{81} 86$ Implementation research, which applies a multidisciplinary approach to understand which interventions and implementation strategies work for whom, and how, can be usefully applied to HSS by identifying and addressing barriers and opportunities to the delivery of high-quality quality care and testing potential solutions. ${ }^{5}$

institutions), who decide not only what needs to be investigated or funding available, but also the methods and approaches to investigate the topic of interest. ${ }^{15}$ Donors from the North also tend to favour short-term research programmes with measurable impact whereas implementation research and health systems strengthening require longer term investments with more uncertain outcomes, and genuine engagement with users, stakeholders and adopters of research outcomes, which is resourceintensive and time-consuming. ${ }^{15}$ Decolonising global health, that 'involves removing all forms of supremacy within all spaces of global health practice, within countries, between countries and at a global level' is key to improving the quality and relevance of implementation research. ${ }^{16}$ Although not formally defined, decolonising global health can be viewed as 'a movement that fights against ingrained systems of dominance and power in the work to improve the health of populations'. ${ }^{17}$ In part this can be achieved by ensuring actors in the South (ie, LMIC institutions) are the ones who take ownership of 
and drive implementation research within their respective contexts. ${ }^{16}$

\section{Addressing the need for high-quality implementation research}

There have been useful guides and articles published on implementation research that aim to ensure rigour. The WHO guide to implementation research, published by the Alliance for Health Policy and Systems Research has the overall aim of improving capacity, particularly within LMICs. ${ }^{5}$ The guide provides a broad overview of implementation research including why it is important, appropriate methods, and explanation of relevant stakeholders. ${ }^{5}$ The Medical Research Council (MRC) of the UK has published guidance on the design and evaluation of complex interventions that has proven to be very influential. ${ }^{18}$ More recently, the MRC has released guidance on how to adapt an evidence-informed intervention to a new context. ${ }^{19}$ Although these guidelines review in detail the essential components to design and evaluate complex interventions, they offer little emphasis or direction on how different theoretical approaches and methods can be applied in practice throughout the different phases of implementation research to address specific research objectives.

This guide aims to address the gaps in the literature in order to provide an overview of the different theoretical approaches and methods to implementation research that can be applied to address specific research objectives, throughout the implementation process. Our guidance, including the cited literature, is based on our expertise in the following multicountry implementation research programmes: Programme for Improving Mental Health care (PRIME), ${ }^{20-23}$ a consortium of research institutions and ministries of health in five LMICs that implemented and expanded coverage of treatment for mental health conditions in primary care and community settings; the Emerging Mental Health Systems in LMICs (EMERALD) programme ${ }^{24}$; ; and a multicountry heAlth Systems StrEngThening programme guided by implementation research and implementation science in sub-Saharan Africa (ASSET) ${ }^{26}{ }^{27}$ We also have experience with participatory research including participatory learning and action (PLA) with women's groups to improve maternal and newborn health outcomes ${ }^{28} 29$ and human-centred design to improve perinatal mental health outcomes. ${ }^{30}$ We aim to use our experience to offer a relatively brief, user-focused guide to help global health actors recognise the important contributions arising from the different theoretical approaches and other methods to implement and report on evaluation of evidence-based and scalable interventions, programmes and practices.

The rest of the paper is organised as follows: initially we offer an overview of the role of theory and describe how this is applied to the different phases of implementation research. We then provide an outline of how the different theoretical approaches and associated methods we present can be applied throughout the implementation research process. This is followed by a discussion of how other methods, such as engagement with stakeholders, need to be embedded within implementation research. We provide case examples for illustration of the above aspects of implementation research that are based on research we have conducted within PRIME, EMERALD and ASSET as well as other research programmes we have been involved in.

\section{Overview of implementation research}

The role of theory applied to implementation research

Within implementation research, the question(s) being investigated will determine the theoretical approach(es) taken and how such investigations are carried out. This applies from the preimplementation phase, which focuses on stakeholder engagement and participatory methods to understand the context where an intervention will be introduced, to the codesign of interventions and implementation strategies, through to approaches adopted to evaluate implementation. This approach can help to ensure both sustainability and transferability.

Implementation research relies heavily on social science theories driven by the relativist paradigm of knowledge. Social science theories (eg, grand theories, such as Marxism $)^{31}$ provide abstract conceptualisations of the social world, that explain the causal relationships between a phenomenon and an outcome. ${ }^{32}$ Social science theories can also be used to guide not only the study design, but also the analysis and understanding of the findings. Box 3 describes different theoretical approaches and other methods relevant to implementation research. Box 4 describes methods and tools that complement the theoretical approaches used within implementation research.

\section{Phases of implementation research}

Ideally, implementation research involves four phases, including: (1) preimplementation; (2) piloting; (3) implementation and evaluation; and (4) postimplementation/dissemination. The core components and methods of implementation research are applied repeatedly throughout the different phases of implementation.

The preimplementation phase is a critical phase that identifies the overall aim of the study and the main theoretical approach and subsequent methodology. ${ }^{26}$ It is also useful at this stage to identify specific objectives that may indicate an additional theory-based approach is required. Key to this phase of research is engaging with stakeholders who are a part of the public health system to ensure that the research objectives address the needs and priorities of the local population. This helps to embed the research programme within the existing health system from the outset. $^{533}$ This can help to ensure local ownership of the research and, therefore, enhance the longer-term sustainability of implementation efforts. ${ }^{533}$ This phase of research also requires involving stakeholders to conduct a careful assessment of the local context to understand 


\section{Box 3 Theoretical approaches to implementation research}

\section{Implementation science}

Implementation determinant frameworks: The compilation of contextual barriers/enablers that are known to influence the ability to effectively implement the evidence-informed practice. Researchers use these frameworks to help identify determinants relevant to their implementation problem and the context within they work. ${ }^{35}$

Implementation theories: A set of analytical principles or statements designed to structure our observation, understanding and explanation of the world. Implementation theories can be used to identify enablers/barriers to implementation as well as the mechanisms by which these operate. ${ }^{35}$

Implementation process models: Describe the process of translating research into practice through different phases of research. ${ }^{35}$

Social science theories: Drawing from the relativist knowledge paradigm, social science theories provide abstract conceptualisation of the social world that explain causal relationships between a phenomenon and an outcome. ${ }^{32}$

Realist evaluation: A way of connecting high-level social theory with empirically observable patterns. 'Middle-range theories' derived from this approach are useful in addressing complexity, including a realist evaluation that accounts for how context influences the underlying mechanisms by which implementation strategies achieve the outcomes. ${ }^{84}$

Programme theory: Describes how a specific intervention is expected to lead to its effects and under what conditions. ${ }^{87}$

Participatory methods: defined as the process of producing new knowledge by 'systematic inquiry, with the collaboration of those affected by the issue being studied, for the purposes of education and taking action or effecting social change'. ${ }^{53}$

and address contextual and behavioural barriers and/or enablers to implement evidence-informed practice. ${ }^{26}$

At the end of the preimplementation phase, a diverse group of stakeholders meet to review the findings, select an initial set of implementation strategies, and develop an initial programme theory (based on the theoretical approach taken) that details the causal processes of how the implementation strategies are expected to achieve the desired outcomes. This process can help to ensure appropriate methods are selected and relevant information is collected throughout the implementation and evaluation phase of research. Finally, conducting an evaluation of costs associated with the implementation and scale-up of the intervention at this stage is important, among other things to secure buy-in from policy-makers. $^{34}$

\section{Box 4 Methodological approaches and tools for implementation research}

\section{Implementation science}

Implementation strategies: Methods or techniques used to enhance the adoption, implementation and sustainability of a clinical programme or practice. ${ }^{4}$ Implementation strategies are selected to overcome identified contextual barriers. Other terminologies to describe these methods include health system strengthening interventions and quality improvement strategies.

Implementation evaluation frameworks: Specify implementation outcomes that can be evaluated to determine implementation effectiveness. ${ }^{35}$

Implementation outcomes: Defined as 'the effects of deliberate and purposive actions to implement new treatment practices, and services and are distinct from service and patient outcomes' ${ }^{40}$ Implementation research uses implementation outcomes (eg, acceptability, fidelity, appropriateness) to assess how well implementation has occurred or to provide insights about how this contributes to one's health status or other important health outcomes. Implementation strategies should be selected to target and improve specific implementation outcomes.

\section{Taxonomies}

The Expert Recommendations for Implementing Change taxonomy: A taxonomy of implementation strategies that allows researchers to apply a common language when describing how evidence-informed interventions are being implemented. Implementation strategies are selected to overcome identified contextual and behavioural barriers. ${ }^{37}$

Effective Practice and Organisation of Care taxonomy: A taxonomy for health system strengthening interventions, that is also similar to the taxonomies for implementation and quality improvement strategies. ${ }^{39}$

\section{Implementation-effectiveness hybrid trials}

Trials that are designed to evaluate both implementation and effectiveness outcomes, in addition to the influence of context on the effectiveness of the intervention. ${ }^{88}$

\section{Literature reviews}

A review of the literature is required to identify and understand the mechanisms behind (ie, theory) how contextual barriers and enablers influence the ability to effectively deliver the evidence-informed practice. ${ }^{76}$

\section{Reporting guidelines for implementation research}

Template for Intervention Description and Replication (TIDieR) checklist: To help improve the quality of descriptions of interventions and therefore their replicability, a group of experts used the Delphi process to develop the TIDieR checklist. ${ }^{89} 90$ It is recommended that researchers use this checklist to help improve the quality and reporting of implementation research for global health.

Getting messier with TIDieR: another checklist has also been developed that helps to address gaps the TIDieR checklist for research conducted outside of trials, such as implementation research. The additional items included in this framework include factors such as how well contextual factors influenced intervention delivery. 
The piloting phase implements and evaluates the set of implementation strategies selected to deliver the evidence-informed practice to ensure it is behaving as intended in a limited number of pilot sites. Specifically, the theoretical approaches adopted will be used to drive the appropriate methods to monitor the effectiveness of implementation strategies in overcoming the contextual determinants they were selected to address. Based on these findings, participatory approaches, such as involving stakeholders in a Theory of Change (ToC) workshop and/or focus group discussions, can be used to adapt the implementation strategies and associated programme theory.

After adjusting the initial programme theory, the implementation and evaluation phase begins an iterative process of evaluating and/or understanding the effectiveness of the set of selected implementation strategies and associated evidence-informed care, on relevant implementation and clinical outcomes. It is paramount at this stage to document and monitor the influence of context on the effectiveness of the implementation strategies on implementation outcomes. All of this is done ensuring the continual engagement of stakeholders and embedding the research into existing health systems, as initiated in the preimplementation phase of the research. For example, conducting regular feedback meetings with health service managers and practitioners to provide updates on implementation strategies and hear their comments on this process is vital.

Lastly, the postimplementation/dissemination phase involves consolidating the engagement activities with stakeholders and users that have been ongoing throughout the earlier stages and together implementing a knowledge exchange, engagement and dissemination plan.

Although we have recommended that implementation research involves four phases, in practice researchers may find themselves in situations where not all of these stages are feasible to design and deliver prospectively; hence some retrospective application of theories and methods (described below) may be necessary.

\section{Theoretical and methodological approaches to implementation research}

Implementation science

Implementation science uses a combination of specialist theories, models, and frameworks to evaluate the effectiveness of implementation strategies and other methods in implementing evidence-informed care on implementation outcomes. ${ }^{35}$ Implementation science also seeks to understand how context influences the effectiveness of implementation strategies on implementation outcomes and how these dynamic changes throughout the implementation process. In what follows, we describe three key theoretical approaches to implementation science.

\section{Determinant frameworks}

Implementation science determinant frameworks offer a theoretical approach to implementation research developed to identify and account for specific contextual barriers and enablers that influence the implementation of evidence-informed practice. ${ }^{35}$ Put simply, these frameworks are designed to answer the question: what determines the success or failure of an implementation effort? Many of these frameworks were designed by synthesising results from empirical studies of barriers and enablers to implementation success, while others were developed using existing frameworks and theories. ${ }^{35}$ Although an investigator may take a positivist approach to use the frameworks to identify determinants, the frameworks can also be operationalised in a way more aligned with critical realism. As an example, these frameworks can be used to theorise how the identified barriers and enablers bring about change by addressing interactions across multiple domains at microlevel, mesolevel and macrolevel. ${ }^{27}$

Applying determinant frameworks to data-collection tools (eg, focus group discussions, interviews) in the preimplementation phase of research provides an evidence-based methodology to identify and address contextual and behavioural barriers and enablers that might otherwise have been missed. Identifying determinants in this phase of research can inform the selection of implementation strategies to support delivery of the evidence-informed practice.

During the implementation and evaluation phase, determinant frameworks are also used to guide the development of data collection tools that are used to monitor and understand the influence of context on the implementation strategies in delivering the evidenceinformed practice. ${ }^{36}$ Determinant frameworks are particularly useful in explaining variation in implementation outcomes across studies. ${ }^{36}$

Determinant frameworks typically address five main categories of factors that can influence implementation efforts: characteristics of the evidence-informed intervention that is being implemented (eg, adaptability and complexity); the external setting (eg, sociocultural, epidemiological and socioeconomic determinants); the internal setting (eg, healthcare facility); characteristics of the users and providers; and processes of implementation. Table 1 provides examples of how different determinant frameworks can be used to identify contextual determinants that influence the delivery of evidence-based care that are relevant to an LMIC setting. The frameworks included in table 1 address characteristics of determinants that are particularly relevant in LMICs, including the external context (eg, lack of resources), characteristics of the healthcare facilities (ability to provide peoplecentred care and lack of supplies to effectively implement the interventions), and characteristics of the users of the healthcare facilities (eg, lack of knowledge about where or when to seek care, lack of empowerment to seek care) as well as the providers (eg, lack of training in how to provide people-centred care). 
Table 1 Examples of how implementation science determinant frameworks can be applied to identify contextual determinants that influence the implementation of evidence-based care

\section{Implementation

framework Framework description \\ Consolidated \\ Framework for \\ Implementation \\ Research (CFIR) ${ }^{91}$ \\ The CFIR includes five categories \\ (domains) of contextual determinants \\ that are known to influence \\ implementation effectiveness: inner \\ setting; outer setting; intervention \\ characteristics; characteristics \\ of individuals involved; and the \\ processes of implementation. ${ }^{91}$ Nested \\ within the different domains are \\ specific contextual determinants that \\ are known to influence implementation \\ outcomes.}

The Context and Implementation

of Complex

Interventions

(CICl) framework ${ }^{3}$

The $\mathrm{CICl}$ framework is both a determinant and evaluation framework that contains seven categories of contextual determinants that can influence the effectiveness of implementation effects. Unique to the $\mathrm{CICl}$ framework, these categories focus on factors external to the health system: geographical; epidemiological sociocultural; socioeconomic; ethical; legal; political.

$\begin{array}{ll}\begin{array}{l}\text { Theoretical } \\ \text { Domains }\end{array} & \begin{array}{l}\text { The implementation of evidence- } \\ \text { informed interventions is dependent } \\ \text { Framework (TDF) }\end{array} \\ & \begin{array}{l}\text { on changing multiple behaviours of } \\ \text { different people. }\end{array} \\ & \text { a synthesis of } 128 \text { determinants } \\ & \text { of behaviour that are known to } \\ \text { influence the implementation of } & \\ \text { evidence-informed care. }{ }^{93} \text { Identifying } \\ \text { these determinants can help to } \\ \text { select appropriate behavioural } \\ \text { change interventions to facilitate the } \\ \text { implementation of evidence-informed } \\ \text { care. }\end{array}$

\section{Description of a}

determinant and associated Example of the determinant in domain the global health literature

Adaptability (intervention

A study in Madagascar on the characteristics): The extent to implementation and evaluation which an intervention can be of a nationwide scale-up of the adapted, tailored and refined Surgical Safety Checklist, found to suit the local needs can influence the effectiveness of of implementing an that the WHO surgical checklist was adaptable to the local setting. A checklist course facilitated multidisciplinary workshops to adapt the checklist to the local environment. ${ }^{92}$ The adaptability of the checklist facilitated implementation of the checklist in this context.

context. $^{91}$

Sociocultural (external

The stigmatising nature of setting): Behavioural pattern surrounding the core of culture including historically derived and selected ideas, and values that are shared among members of a group can influence effectiveness of delivering evidence-informed care in a new context. ${ }^{3}$

Knowledge of scientific rationale (knowledge) : An awareness of the existence of something.

Fear (emotion): A complex reaction pattern involving experiential, behavioural, and physiological elements by which the individual attempts to deal with a personally significant matter or event. ${ }^{93}$

\section{A qualitative study in the} preimplementation phase of f a quality improvement project used the TDF to explore reasons for missed opportunities for vaccination among children in Kano, Nigeria. Findings revealed that several determinants of behaviours including caregivers lack of knowledge of the benefits in vaccinating children. There was also the complex emotion of fear. People were afraid of the side effects of the vaccination. ${ }^{95}$

\section{Implementation strategies}

We have noted some confusion in the literature with the terminology used for implementation strategies, where in some instances they are referred to as "components of a complex intervention'. In implementation science terms, implementation strategies are separate from any health-focused intervention. Essentially, implementation strategies are a tool used within the discipline: they are the implementation approaches that deliver and improve the uptake of an evidence-informed practice. ${ }^{35}$

Implementation strategies are selected to overcome identified contextual barriers (which a determinant framework and a programme theory would have identified) to deliver the evidence-informed practices identified in the preimplementation phase of research using tools such as determinant frameworks. ${ }^{4}$ As an example, a common implementation strategy applied in implementation research for global health is task sharing using community health workers to deliver the evidenceinformed care. When selecting different implementation strategies, it is useful for researchers, jointly with study stakeholders, to theorise how they expect the strategies to play out once implemented within different contexts. This theorising of context and its relationship with the intervention will be critical for informing how implementation strategies in the delivery of the evidence-informed practice are subsequently evaluated and monitored over time.

There is inconsistent labelling of implementation strategies used for implementation research. ${ }^{37}$ This has resulted in difficulty in synthesising results across studies to understand the effectiveness of specific methods in 
Table 2 Examples of implementation strategies (health system strengthening interventions) for implementation research in global health

\begin{tabular}{|c|c|}
\hline $\begin{array}{l}\text { Implementation } \\
\text { strategy }\end{array}$ & Description \\
\hline Task-shifting & $\begin{array}{l}\text { Use of lay health workers to deliver evidence- } \\
\text { informed psychological therapies to improve } \\
\text { depression outcomes in Zimbabwe. }^{96}\end{array}$ \\
\hline Text messages & $\begin{array}{l}\text { Using text message to encourage patients to } \\
\text { adhere to HIV treatment. }{ }^{97}\end{array}$ \\
\hline $\begin{array}{l}\text { Education and } \\
\text { training }\end{array}$ & $\begin{array}{l}\text { Training lay health workers to use a novel vital } \\
\text { sign device to detect pre-eclampsia and shock } \\
\text { to improve maternal mortality or morbidity as } \\
\text { well as implementation effectiveness in } 10 \\
\text { countries across Africa, India and Haiti. }{ }^{98}\end{array}$ \\
\hline $\begin{array}{l}\text { Mobile health } \\
\text { technology }\end{array}$ & $\begin{array}{l}\text { Using mobile health technology to deliver a 6- } \\
\text { week psychoeducational intervention to reduce } \\
\text { depressive symptoms among individuals with } \\
\text { diabetes or hypertension. }\end{array}$ \\
\hline
\end{tabular}

a given context. ${ }^{38}$ However, methods are available that can help with selecting and labelling relevant implementation strategies, including a tool developed by The Expert Recommendations for Implementing Change (ERIC) study. ${ }^{37}$ The ERIC tool offers a compilation of implementation strategies that are known to be effective in addressing specific contextual barriers and enablers. Further, the Effective Practice and Organisation of Care taxonomy is a compilation of health system strengthening interventions. ${ }^{37}{ }^{39}$ Both taxonomies share the same objective of using a common language to label the methods (ie, implementation strategies or health system strengthening interventions) used to deliver the evidenceinformed practice that will help with the generalisation of findings from one research programme to another. Table 2 describes implementation strategies commonly used for implementation research in global health.

\section{Evaluation frameworks}

Evaluating the effectiveness of a novel treatment requires the selection of appropriate clinical outcomes. Similarly, implementation strategies need to be evaluated to assess their effectiveness, for which appropriate outcomes need to be selected. To achieve this, implementation outcomes are selected that are supported by a social science theory, or implementation science theories or frameworks. ${ }^{35}$ Evaluation frameworks are a tool that can be applied to assist researchers in selecting appropriate implementation outcomes to evaluate for a particular set of implementation strategies. ${ }^{35}$

Initially, determinant frameworks are used to identify barriers and enablers to implementation, followed by selecting implementation strategies to overcome identified barriers. Implementation outcomes should be selected that capture the effectiveness of implementation strategies and contextual or behavioural determinants. As an example, if there is a lack of healthcare workers to deliver a previously evaluated care intervention (determinant) then approaches such as task shifting with community healthcare workers are used to address this issue (implementation strategiesotherwise known as the 'intervention'). A relevant implementation outcome would therefore be coverage (ie, the proportion of the population receiving care prior to implementation compared with after implementation). Proctor et $a l^{40}$ have published a taxonomy of implementation outcomes that offers a list of conceptually distinct outcomes for evaluation-including acceptability, adoption, appropriateness, feasibility, fidelity, implementation cost, penetration and sustainability. There are other useful evaluation frameworks available to help select implementation outcomes, including the reach, effectiveness, acceptability, implementation and maintenance framework. ${ }^{41}$

It is important to evaluate a combination of relevant implementation outcomes at multiple time points throughout the implementation process. ${ }^{40}$ It is also imperative to monitor and theorise about the influence of context on the effectiveness of the implementation strategies on implementation outcomes. Determinant frameworks can be used to guide data collection tools to assess how context influences specific implementation strategies and associated implementation outcomes. Table 3 provides examples of how implementation outcomes have been applied to implementation research in LMICs.

\section{Implementation theories}

Whereas social science theories explain the causal mechanisms between certain phenomena and an outcome, ${ }^{32}$ implementation theories are a theoretical approach typically developed or adapted by researchers to specifically understand or explain certain aspects of implementation. ${ }^{35}$ Researchers select a implementation theory to analyse the mechanisms of the implementation process that can help to explain why implementation efforts are successful (or not). How a researcher views the social world shapes how the implementation theory is applied. Typically, implementation theory emerges from different knowledge paradigms, some of which may draw on wider social theories of behaviour or incorporate wider social forces.

In the preimplementation phase, implementation theories can be applied not only to identify determinants to implementation, but also to understand the mechanisms by which the implementation strategies will deliver the evidence-informed practice. Moreover, throughout the implementation and evaluation phase, a mixed-methods design, guided by an implementation theory can be used to understand barriers/enablers to implementation as well the mechanisms by which the implementation strategies work, for whom and how. An example of how an implementation science theory has been applied in practice can be found in online supplemental file A, table 1 . Broad description of several implementation theories is offered by Nilsen. ${ }^{35}$ 
Table 3 Examples of how implementation outcomes have been applied to implementation research to evaluate specific implementation strategies in global health

Example of research study
A stepped-wedge cluster randomised trial
evaluating the effectiveness of a novel vital
sign device in detecting pre-eclampsia
and shock to improve maternal mortality
or morbidity as well as implementation
effectiveness in 10 countries across Africa,
India, and Haiti. ${ }^{98}$ The RE-AIM framework
was used to evaluate implementation
outcomes.

Implementation strategy (ies)

Task shifting with community health workers to overcome lack of trained nurses and doctors to detect and treat pre-eclampsia, Education and training to improve skills to accurately detect and treat pre-eclampsia.
Implementation outcomes assessing effectiveness of implementation strategy

Coverage-Difference in proportion of women with blood pressure measurements pre and post implementation; Fidelity -no/proportion of sites that delivered the training as intended;

delive

A study protocol for a randomised controlled, non-inferiority trial aims to test the effectiveness of using general health workers to deliver mental healthcare in primary healthcare settings, compared with specialist medical care delivered by psychiatric nurses for patients with severe mental illness. ${ }^{100}$

A process evaluation of a primary care
paediatric intervention (Practical Approach
to Care Kit (PACK) Child) piloted in 10
healthcare clinics in the Western Cape,
South Africa. PACK Child comprised clinical
decision support tool (PACK Child guide),
training programme and health system
strengthening components.

Task shifting using general healthcare workers to overcome lack of specialist medical care and improve the proportion of patients receiving effective treatment.

Education, cascade training model, supervision with regular updates as guidance and policies change.
The fidelity of the task shared mental healthcare in delivering the guidelinebased care, was measured through structured evaluation of clinical followup forms by independent psychiatrists, including prescribing, risk assessment, psychoeducation and symptom review. ${ }^{100}$

Implementation fidelity - Use of the PACK Child guide according to training programme.

Acceptability-Stakeholder perspectives of impact of the intervention on child healthcare.

RE-AIM, reach, effectiveness, acceptability, implementation and maintenance.

\section{Realist evaluations}

Realist evaluations are theory-based evaluations based on realist philosophy ${ }^{42}$ that are gaining popularity in global health. ${ }^{44}$ Realist philosophy was designed to sit between the positivist and relativist approaches. Realism assumes that nothing works for everyone everywhere and that the effects of interventions are largely determined by context. Therefore, a realist evaluation can help to understand and evaluate the complexity surrounding implementation research by conceptualising what works, for whom and how. ${ }^{42}$ Evaluating this complexity is useful in developing an understanding of how an intervention can be adapted to a new context and scaled up. ${ }^{45}$

Initially, a programme theory is developed (based on previous research and knowledge) that explains how the intervention is expected to produce the intended outcomes and in what contexts this can be achieved. ${ }^{42}$ The programme theory is then revisited and modified throughout the evaluation to arrive at a final theory. This approach is otherwise known as the Context-MechanismsOutcomes configuration. Here, context refers to the conditions in which an intervention is introduced (sociocultural, political, socioeconomic, ethical, epidemiological) which can occur at the microlevel, mesolevel and macrolevel. ${ }^{46}$ A mechanism refers to how social actors reason and react to the available resources (ie, the intervention), to bring about change in a specific context. ${ }^{47}$ Once mechanisms are activated in a specific context, they can be identified and measured through their unexpected or expected outcomes. ${ }^{48}$ When applied to implementation research, we envisage context triggering the mechanisms due to the introduction of the implementation strategy(ies) embedded within a broader programme. An example of applying realist theory to implementation research is a study that evaluated how different contexts influenced the mechanisms responsible for divergent outcomes following the implementation of a user fee exemption policy for caesarean section at two hospitals in Benin (online supplemental file A, table 2). ${ }^{49}$

\section{Participatory approaches within implementation research}

Participatory research is underpinned by a particular view of the social world that interventions/implementation strategies are socially constructed through interactions. Indeed, participatory research draws on the paradigms of critical theory and constructivism, common to the social sciences. ${ }^{50}$ Participatory methods involve stakeholders, including research participants (ie, patients and their carers), are essential to ensure that the voices of 'experts by experience' are heard and to gain local buy-in and ensure acceptability and sustainability for the longer term. ${ }^{51} 52$ Participatory research has been defined as the process of producing new knowledge by 'systematic inquiry, with the collaboration of those affected by the issue being studied, for the purposes of education and taking action or effecting social change'. ${ }^{53}$ 
Although there are different applications of participatory research, they all share the common objective of improving social and economic conditions to effect change and to reduce the distrust of the people being studied. ${ }^{53}$ Participatory research methods are particularly relevant to disadvantaged communities and, therefore, some communities within resource-poor settings within LMICs, which are often excluded from the planning and implementation of health interventions. The inclusion of a variety of stakeholders integral to the delivery and uptake of interventions supports the development of an intervention's theoretical foundation unencumbered by a positivist framework. ${ }^{54}$ These methods also support selfempowerment by removing barriers and promoting environments within which communities can increase their capacity to identify and solve their own problems. ${ }^{55}$

\section{Participatory action research}

Participatory action research (PAR) is an example of such methodology that represents a broad family of research approaches that emphasise social change, transformation. It is a self-reflective process, involving both researchers and participants, which undertakes action based on the local context and aims to empower participants to improve health and reduce health inequities. ${ }^{50}$ PAR is a cyclical process where action is achieved through participants identifying a problem, collecting and analysing relevant information, developing an action and reflecting on the action. The process of PAR is expected to be empowering and lead to people having increased control over their lives and communities. ${ }^{50}$ Similar to PAR is PLA, a form of action research that is grounded in the participation of people in a local community while being facilitated through local community members instead of an external researcher. PLA enables and empowers people through problem-solving through a process of sharing, learning, action and reflection. ${ }^{56}$

\section{Human-centred design}

Human-centred design is another participatory research approach, which allows for the meaningful engagement of key stakeholders, including the intervention's target population, in all implementation research phases. It comprises five stages of intervention development and evaluation: (1) Empathise-identification of stakeholder perceptions, needs, goals and priorities; (2) Defineagreement of a priority challenge(s) to be addressed; (3) Ideate-development of potential interventions; (4) Prototype-refinement of interventions and (5) Testevaluation and further refinement. Although initially used within the private sector, its potential utility within the field of global health has been identified through recent research. ${ }^{57}$ The use of prototypes to refine an intervention and implementation process prior to pilot and trial evaluation is a key feature as this allows for initial 'bottom-up' identification of potential barriers to success and unintended consequences prior to largescale research investment.

\section{Participatory ToC to develop a programme theory}

Participatory ToC methodology is a form of participatory research, which involves key stakeholders and aims to improve the understanding of how and why a programme works through the development of a programme theory. ${ }^{58}$ Programme theories are increasingly being used with implementation research for global health to describe how an interventions intends to bring about change and the relationships between inputs, outputs and outcomes, unintended consequences and basic assumptions. ${ }^{59}$ The expectations of how a programme or intervention might work as articulated in a programme theory can subsequently be evaluated through a study design that includes process and outcome measures (eg, a process evaluation or hybrid trial).

The ToC process can support the development of shared goals among stakeholders and promote accountability. The initial programme theory can be strengthened by incorporating mid-range theories such as a realist evaluation to help explain causal mechanisms that are particularly relevant to the intervention. ${ }^{60}$ Strengthening the programme theory can also be achieved by incorporating key implementation outcomes and contextual determinants selected from different implementation science frameworks. Indeed, there are methods available that can be used to help to merge implementation science methods into ToC workshops. ${ }^{61}$ A recommended approach to developing a ToC programme theory or map involves working with stakeholders (including people with lived experience of ill health and their carers) to reach agreement as to the intended impact of an intervention; then working backwards to determine intermediate and short-term outcomes necessary to achieve the desired impact. ${ }^{62}$ Ideally, ToC programme theories are developed and refined throughout the process of implementation.

Table 4 provides examples of participatory research. As an example, ToC workshops were used to develop a programme theory for the PRIME in Ethiopia, India, Nepal, South Africa and Uganda. ${ }^{21}{ }^{22}$ This programme theory described the hypothesised causal pathway from entry into each district site to achieving changes in treatment coverage for people living with mental, neurological and substance use disorders in that district.

\section{Engagement and knowledge exchange activities}

A key outcome of implementation research is to ensure scalable, sustainable change from the original research. Ensuring implementation research is participatory, by creating opportunities involving engagement with key stakeholders, is key to achieving that change. Several other disciplines have described such processes, including 'knowledge mobilisation', ${ }^{63}$ the use of 'embedded researchers' ${ }^{64}$ 'co-production' methods between researchers and practitioners, ${ }^{65}$ as well as studies examining how societal impact stems from research. ${ }^{63667}$ Generally these are intended to create opportunities for stakeholders to understand, adopt and sustain outcomes 
Table 4 Examples of participatory methods in implementation research

\begin{tabular}{|c|c|}
\hline Method & Example \\
\hline $\begin{array}{l}\text { Participatory } \\
\text { action research }\end{array}$ & $\begin{array}{l}\text { There have been several cluster randomised trials evaluating the effect of women's groups using } \\
\text { participatory learning and action (PLA) to improve the delivery of essential newborn care practices, on } \\
\text { neonatal mortality. }{ }^{28} \text { Women's groups involve a four-phase PLA cycle. Phase } 1 \text { identifies and prioritises } \\
\text { problems during pregnancy, delivery, and post partum; phase } 2 \text { plans the action; phase } 3 \text { implements } \\
\text { locally feasible strategies to address the priority problems, and; phase } 4 \text { assesses their activities. }{ }^{28} \text { This } \\
\text { methodology draws on Paolo Freire's work, which when applied to health infers that health education is } \\
\text { more empowering if it involves dialogue and problem solving, rather than message giving. }{ }^{103}\end{array}$ \\
\hline
\end{tabular}

Human-centred The Adolescent 360 (A360) project aimed to improve uptake of contraceptives among adolescent girls in design Ethiopia, Nigeria and Tanzania. A360 used a human-centred design approach to develop interventions tailored to each country in conjunction with adolescents and other key stakeholders. ${ }^{104}$ Interventions included financial messaging to support adolescents and their husbands with family planning in Ethiopia, entrepreneurial skills and contraceptive counselling among young Tanzanian girls, maternal and child health and skill building sessions for adolescents and their husbands in Northern Nigeria and health literacy and skill-building for unmarried adolescents in Southern Nigeria. Implementation and evaluation of each intervention included active engagement of stakeholders as well as the development of an extensive knowledge exchange platform.

\begin{tabular}{|c|c|}
\hline Photovoice & $\begin{array}{l}\text { A study in rural Nepal that aimed to investigate whether community based participatory research can help } \\
\text { women in a vulnerable low-income country understand and adapt to important environmental challenges } \\
\text { related to climate change and whether this activity can help promote mental health. } \\
\text { Participants learnt how to use cameras and then formulated questions related to climate change and mental } \\
\text { health (eg, how will water scarcity affect our well-being?'). Participants took photos related to their questions } \\
\text { and shared their images during sessions with other participants, where they talked about the photos using a } \\
\text { standard photovoice discussion format. In the final session, the research team and participants reviewed the } \\
\text { themes that had emerged from the discussions and showcased their photos in the community. } \\
\text { Findings suggested that photovoice can help identify local and existing resources, generate adaptive } \\
\text { strategies and promote mental health. }\end{array}$ \\
\hline $\begin{array}{l}\text { Participatory } \\
\text { Theory of } \\
\text { Change (ToC) } \\
\text { methods }\end{array}$ & $\begin{array}{l}\text { The Programme for Improving Mental healthcare (PRIME) was a large multicountry study that aimed to } \\
\text { provide research evidence for the integration of mental healthcare into primary healthcare in Ethiopia, } \\
\text { India, Nepal, South Africa and Uganda. }{ }^{106} \text { PRIME used ToC workshops to develop a structured logical and } \\
\text { evidence-based ToC map for a mental healthcare plan in each district that contextualised the plans and } \\
\text { obtained stakeholder buy in. }{ }^{2122}\end{array}$ \\
\hline
\end{tabular}

from research, or create opportunities for 'productive interactions'. ${ }^{68}$ These activities can be parts of intervention design itself (ie, in codesign or coproduction activities), and at other times they are activities occurring in parallel to the research and considered to be activities which complement the research process in facilitating its adoption and scale-up. Within the context of activities that support scale-up and adoption of research to support implementation activities, there has been extensive research conducted into how to overcome barriers in bringing research evidence closer to policymaking. ${ }^{69}$ One approach developed to specifically address this barrier is the 'policy lab' approach. ${ }^{71}$ Envisaged as a process for engaging evidence and policy-making and not an isolated activity, these labs serve to build a coalition through participation of diverse communities, work on the language and presentation of evidence, and engage policy-makers early to respond when windows of opportunity for changing policy emerge. ${ }^{71}$

Further components of implementation research, beyond the scope of this guide, are specialist topic areas, such as economic evaluations, literature reviews and implementation-effectiveness hybrid study designs. We have offered an overview of these in online supplemental material B for the interested readers.

\section{Conclusions}

This guide is intended to address gaps not covered by existing publications or guidance, regarding how best to set up and conduct high-quality implementation research in global health settings. Given implementation research is a relatively novel and niche field that involves expertise of complex methodologies from specialist disciplines it is unsurprising it is still a challenge to conduct and report it consistently across studies. To alleviate the ambiguity surrounding theories, methodologies and tools applied to implementation research, we have described how different knowledge paradigms, with distinctive perspectives on reality, offer contributions that are essential for high-quality implementation research. We have provided guidance through an overview of core methods and approaches offered through the divergent knowledge paradigms and how these can be applied at different phases of research. To help conceptualise how the different approaches to implementation research are applied, figure 1 depicts core components and essential methodologies that we recommend global health 

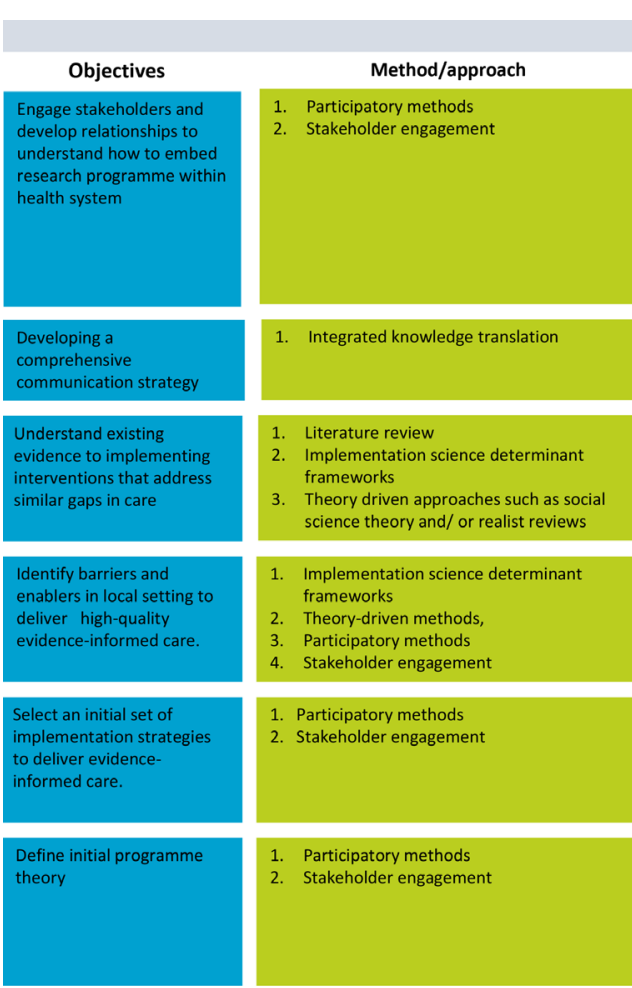
frameworks
2. Theory-driven methods,
. Participatory methods

4. Stakeholder engagement

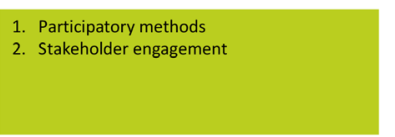

1. Participatory methods
2. Stakeholder engagement
Pre-implementation phase

\section{Description}

1. Identify key people and organizations that might have an influence or interest in the implementation of the programme.

2. Stakeholder mapping including assessing how much influence and interest they have in relation to the topic to determine how and to what extent they can be involved in knowledge utilization/translation. This involves identifying those who benefit from changes and those who can influence changes across policy, practitioner and patient groups.

Engage with all relevant stakeholders early on to obtain implementation buy in and understand the gap in delivery of evidence informed care and what the needs and priorities of the community and health system.

Develop a plan to ensure there will be continuous engagement of stakeholders who can action research outcomes by creating opportunities for engagement through establishing user committees and participatory engagement activities to use throughout the implementation process.

1. Identify the need, use for knowledge translation to ensure timely solutions to implementation problems while the research is taking place. Develop a knowledge exchange strategy to guide the interaction and sharing of research methods, findings and other related evidence based upon step which includes ways in which the strategy outputs are assessed.

1. Literature review to Identify interventions that have been used to address a similar gap in de livery of evidence-informed care.

2. Use of theory (implementation theory, middle-range theory or social theory) to guide the review to understand mechanisms associated with implementation and synthesize findings on the associated contextual barriers/enablers and/or;

3. Use of determinant framework to guide a literature review to identify contextual and/or behavioural barriers to implementation .

1. Use determinant frameworks to guide the development of data collection tools for different studies (i.e. focus group discussions, semistructured interviews, ethnographic observations) to Identify barriers/enablers to implementation.

2. Use of theory (implementation theory, middle-range theory or social theory) to guide the development of data collection tools to identify
structured interviews, ethnographic observations) to Identify barrier/enablers to implemtang barriers to implementation and understand the mechanisms by which this occurs.

3. These approaches should be done using participatory methods involving relevant stakeholders.

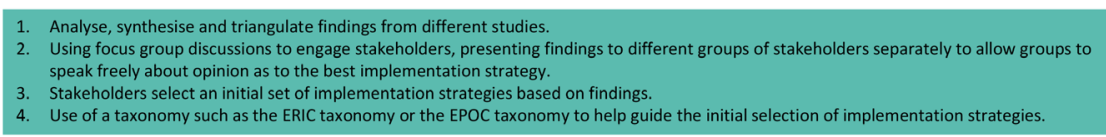

4. Use of a taxonomy such as the ERIC taxonomy or the EPOC taxonomy to help guide the initial selection of implementation strategies.

1. Present findings from the pre-implementation phase of research to all stakeholders.

2. Use participatory theory of change workshops with stakeholders including patients and public to:

- Develop an initial programme theory that details the causal processes the im

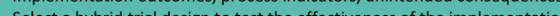

ategies on implementation and/or clinical outcomes.

- Determine whether a quasi-experimental or randomised trial is appropriate to test the implementation strategies.

\section{Piloting phase}

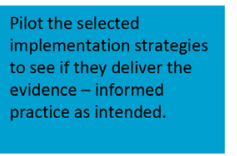

1. Implementation science determinant and
evaluation frameworks
2. Theory driven methods
3. Participatory methods
4. Stakeholder engagement

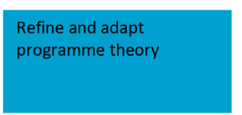

1. Participatory methods
2. Stakeholder engagement
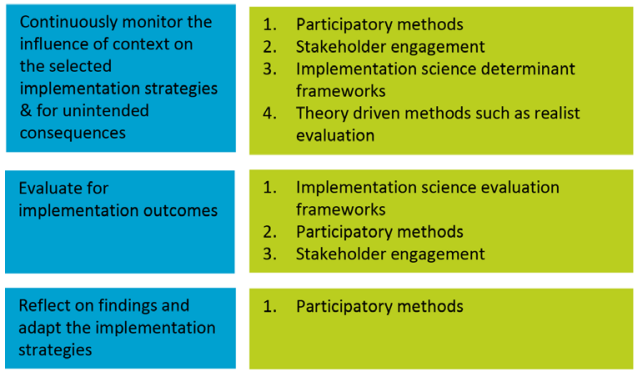

1. Participatory methods

strategies

\section{Stakeholder mapping \& analysis Strategic dissemination}
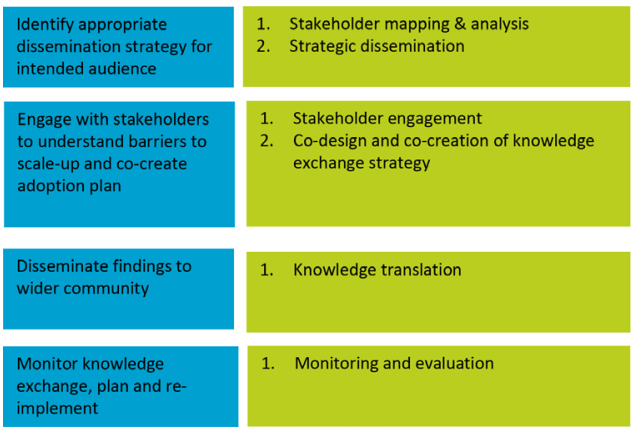

1. Monitoring and evaluation

Figure 1 Methods and core components recommended for the different phases of implementation research. EPOC, Effective Practice and Organisation of Care; ERIC, Expert Recommendations for Implementing Change; RE-AIM, reach, effectiveness, acceptability, implementation and maintenance.
1. Use determinant frameworks to guide the development of data collection tools to Identify barriers/enablers to implementation. Use of theory-driven methods (implementation theory, middle-range theory or social theory) to guide the development to data collection tools to identify barriers to implementation and understand the mechanisms by which this occurs.

Use of evaluation frameworks to guide the development of data collection tools to evaluate relevant implementation outcomes including propriateness, and feasibility.

. Use data collection tools for participatory methods such as focus-group discussion, interviews with key stakeholders, co-design methods.

\section{Synthesize and triangulate findings. \\ 2. Present findings in focus group discussions to understand if intervention is behaving as intended. \\ me theory and select any additional implementation strategies if require \\ . Use of a taxonomy such as the ERIC taxonomy or the EPOC taxonomy to help adapt the set of implementation strategies to any relevant.}

\section{Implementation and evaluation phase}

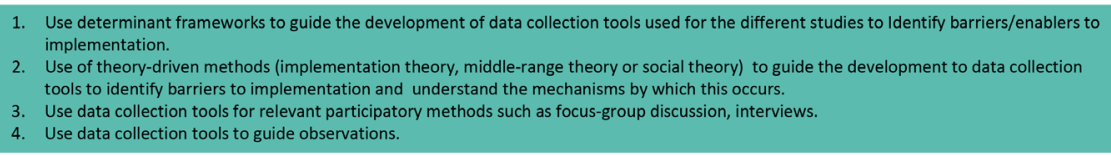

1. Using an implementation evaluation framework such as RE-AIM to design data collection tools to evaluate for implementation outcomes.

2. Use data collection tools to collect outcome measures either with participatory methods or structured surveys.

. Align findings to research objectives, context, mechanisms and implementation strategies.
1. Focus group discussions with stakeholders to reflect on findings and who suggest any modifications.

2. Participatory theory of change workshops to adjust programme theory and select/adapt and of the implementation strategies

\section{Post-implementation/Dissemination phase}

\section{Map stakeholder groups to specific outcomes from the implementation research and design dissemination strategies accordingly. Tailored message and dissemination channels (e.g. social media, mainstream media, newsletter, policy briefs) designed and created for each stakeholder group} will assess evidence and understand barriers to successfully integrate the intervention into their health system and learning into policy and practice.

Conduct workshops with members of the community and patient representative groups. Trained foc
1. Use of policy engagement workshops (eg Policy labs) held with local and regional policy makers, healthcare workers, funders/donor. Experts

\section{Present completed findings, summarised appropriately for the target audience. \\ es as appropriate. \\ 3. Develop policy briefings and pamphlets, with infographics and accessible language to action dissemination plan.}


researchers can apply at the different phases of their research.

The expertise from specialist disciplines required for implementation research also emphasises the need for extensive capacity building in both high-income countries, and LMICs. Further work is also needed to ensure the approaches used for implementation research are adapted and new ones developed to suit the different contexts in LMICs and that, importantly, this is driven by actors within those countries (ie, the global South). Funders such as the National Institute of Health Research in England increasingly emphasise the importance of not only capacity building, but also community engagement and involvement as core criteria for funding. ${ }^{72}$

High-quality evidence-informed implementation research in LMICs will be key to achieving Universal Health Coverage (UHC) with high-quality care. There are multiple reasons that help to explain the lack of highquality implementation research in LMICs. Importantly, one cannot overlook the issues with accountability, power relations and divergent interests mainly driven by the global north, strongly informed by colonialism. ${ }^{15} 73$ As an example, some donors struggle to align their approaches and priorities with LMIC needs and priorities and are more interested in funding programmes with shortterm outcomes and known impacts. ${ }^{15}$ This undermines programmes such as health system strengthening and implementation research that have longer term impacts, reliant on local buy-in. Improving our ability to deliver high-quality implementation research will require more effort to decolonise global health. Of particular relevance is the understanding that implementation research must be driven by communities in the global south, and non-Western researchers, as they hold the knowledge surrounding the local context and the needs and the priorities of the population. To do this successfully, a concurrent emphasis on capacity-building in within LMIC, as discussed above, is essential with leadership of research initiated and taken more commonly by local actors.

We hope this guide can help to build capacity for global health actors in both LMIC and high-income countries. We also hope our guide can help donors understand the requirements of high-quality implementation research, which may need longer-term investments with uncertain outcomes. It is our aspiration that facilitating widespread and shared understanding of the theoretical and methodological approaches needed to conduct effective, robust implementation studies in LMICs can help bring to scale life-saving interventions and achieve UHC goals.

\section{Author affiliations}

${ }^{1}$ Centre for Implementation Science, Department of Health Service and Population Research, King's College London, London, UK

${ }^{2}$ Institute of Psychiatry, Psychology and Neuroscience, Health Service and Population Research Department, Centre for Global Mental Health, King's College London, London, UK

${ }^{3}$ Centre for Innovative Drug Development and Therapeutic Trials for Africa (CDTAfrica), College of Health Sciences, Addis Ababa University, Addis Ababa, Ethiopia
}

${ }^{4}$ Delft University of Technology, Delft, The Netherlands

${ }^{5}$ King's College London, London, UK

${ }^{6}$ University of Cape Town, Rondebosch, South Africa

${ }^{7}$ University of East Anglia Faculty of Medicine and Health Sciences, Norwich, UK ${ }^{8}$ Research Support Centre, College of Health Sciences, University of Zimbabwe, Harare, Zimbabwe

${ }^{9}$ Pravara Institute of Medical Sciences, Loni, Maharashtra, India

${ }^{10}$ Health Service \& Population Research Department, King's College London,

London, UK

Twitter Nadine Seward @nadineseward and Saba Hinrichs-Kraples @sabziehin

Contributors NSew is the guarantor and responsible for the overall content of the paper; NSew drafted the paper NSev conceptualised the idea for the paper; NSew and NSev offered insights into implementation science. JM offered details around process evaluations and context. SH-K offered details surrounding policy research TTS and NSev provided details to participatory research. CH, NSew, TTS, RS, GT, RV, $\mathrm{RA}$ and $\mathrm{CL}$ provided details of implementation research in Global Health. JM, SH-K, $\mathrm{CH}, \mathrm{RS}, \mathrm{GT}$ and NSev reviewed several drafts of the manuscript;

Funding NSew, $\mathrm{CH}$, Prince and NSev are funded by the National Institute of Health Research (NIHR) Global Health Research Unit on Health System Strengthening in SubSaharan Africa, King's College London (GHRU 16/136/54) using UK aid from the UK Government to support global health research. Sevdalis and Thornicroft's research is further supported by the NIHR Applied Research Collaboration South London at King's College Hospital NHS Foundation Trust, and by the ASPIRES research programme in LMICs (Antibiotic use across Surgical Pathways-Investigating, Redesigning and Evaluating Systems), funded by the Economic and Social Research Council. Sevdalis and Thornicroft are members of King's Improvement Science, which offers cofunding to the NIHR ARC South London and is funded by King's Health Partners (Guy's and St Thomas' NHS Foundation Trust, King's College Hospital NHS Foundation Trust, King's College London and South London and Maudsley NHS Foundation Trust) and Guy's and St Thomas' Foundation. Hanlon additionally receives funding support from AMARI as part of the DELTAS Africa Initiative (DEL-15-01).

Disclaimer The views expressed here are not necessarily those of the NIHR or the Department of Health and Social Care, the NHS, the ESRC, AMARI or the DELTAS Africa Initiative.

Competing interests NSew is the director of the London Safety and Training Solutions, which offers training in patient safety, implementation solutions and human factors to healthcare organisations and the pharmaceutical industry. The other authors have no conflicts of interest to declare.

Patient consent for publication Not applicable.

Provenance and peer review Not commissioned; externally peer reviewed.

Data availability statement Not applicable.

Supplemental material This content has been supplied by the author(s). It has not been vetted by BMJ Publishing Group Limited (BMJ) and may not have been peer-reviewed. Any opinions or recommendations discussed are solely those of the author(s) and are not endorsed by BMJ. BMJ disclaims all liability and responsibility arising from any reliance placed on the content. Where the content includes any translated material, BMJ does not warrant the accuracy and reliability of the translations (including but not limited to local regulations, clinical guidelines, terminology, drug names and drug dosages), and is not responsible for any error and/or omissions arising from translation and adaptation or otherwise.

Open access This is an open access article distributed in accordance with the Creative Commons Attribution Non Commercial (CC BY-NC 4.0) license, which permits others to distribute, remix, adapt, build upon this work non-commercially, and license their derivative works on different terms, provided the original work is properly cited, appropriate credit is given, any changes made indicated, and the use is non-commercial. See: http://creativecommons.org/licenses/by-nc/4.0/.

\section{ORCID iDs}

Nadine Seward http://orcid.org/0000-0002-4821-9437

Charlotte Hanlon http://orcid.org/0000-0002-7937-3226

Saba Hinrichs-Kraples http://orcid.org/0000-0001-9043-8847

Jamie Murdoch http://orcid.org/0000-0002-9021-3629

Rahul Shidhaye http://orcid.org/0000-0001-9365-7164

\section{REFERENCES}

1 Al-Janabi A, Al-Wahdani B, Ammar W, Annegret A-J, Batool A-W, Walid $A$, et al. Bellagio declaration on high-quality health systems: 
from a quality moment to a quality movement. Lancet Glob Health 2018:6:e1144-e1145.

2 Kruk ME, Gage AD, Arsenault C, et al. High-quality health systems in the sustainable development goals era: time for a revolution. Lancet Glob Health 2018;6:e1196-252.

3 Pfadenhauer LM, Gerhardus A, Mozygemba K, et al. Making sense of complexity in context and implementation: the context and implementation of complex interventions $(\mathrm{CICl})$ framework. Implement Sci 2017;12:21.

4 Proctor EK, Powell BJ, McMillen JC. Implementation strategies: recommendations for specifying and reporting. Implement Sci 2013;8:139

5 Peters DTN, Adam T. Implementation research in health: a practical guide. alliance for health policy and systems research. World Health Organization, 2013.

6 Weiss C. Evaluation: methods for studying programs and policies. Pearson College Division, 1998

7 Chen HT. Theory-driven evaluation. In: Methison S, ed. Encyclopedia of evaluation. Thousand Oaks: Sage Publications, 2004. : 415-9p..

8 Chen HT. Interfacing theories of program with theories of evaluation for advancing evaluation practice: Reductionism, systems thinking, and pragmatic synthesis. Eval Program Plann 2016;59:109-18.

9 Gilson L. Health policy and systems research: a methodology reader. World Health Organization, Alliance for Health Policy and Systems Research, 2012.

10 Gilson L, Hanson K, Sheikh K, et al. Building the field of health policy and systems research: social science matters. PLoS Med 2011;8:e1001079.

11 Koplan JP, Bond TC, Merson MH, et al. Towards a common definition of global health. Lancet 2009;373:1993-5.

12 Abimbola S. On the meaning of global health and the role of global health journals. Int Health 2018;10:63-5.

13 Theobald S, Brandes N, Gyapong M. Implementation research: new imperatives and opportunities in global health. The Lancet 2018;392:2214-28.

14 Alonge O, Rodriguez DC, Brandes N, et al. How is implementation research applied to advance health in low-income and middleincome countries? BMJ Glob Health 2019;4:e001257.

15 Spicer N, Agyepong I, Ottersen T, et al. 'It's far too complicated': why fragmentation persists in global health. Global Health 2020;16:60

16 Abimbola S, Pai M. Will global health survive its decolonisation? The Lancet 2020;396:1627-8.

17 Khan M, Abimbola S, Aloudat T, et al. Decolonising global health in 2021: a roadmap to move from rhetoric to reform. BMJ Glob Health 2021;6:e005604.

18 Moore GF, Audrey S, Barker M, et al. Process evaluation of complex interventions: medical Research Council guidance. BM 2015;350:h1258

19 Moore G, Campbell M, Copeland L, et al. Adapting interventions to new contexts-the adapt guidance. BMJ 2021;374:n1679.

20 Lund C, Tomlinson M, De Silva M, et al. Prime: a programme to reduce the treatment gap for mental disorders in five low- and middle-income countries. PLoS Med 2012;9:e1001359.

21 Breuer E, De Silva MJ, Fekadu A, et al. Using workshops to develop theories of change in five low and middle income countries: lessons from the programme for improving mental health care (prime). Int J Ment Health Syst 2014;8:15.

22 Breuer E, De Silva MJ, Shidaye R, et al. Planning and evaluating mental health services in low- and middle-income countries using theory of change. Br J Psychiatry 2016;208 Suppl 56:s55-62.

23 Hanlon C, Luitel NP, Kathree T, et al. Challenges and opportunities for implementing integrated mental health care: a district level situation analysis from five low- and middle-income countries. PLoS One 2014;9:e88437.

24 Petersen I, van Rensburg A, Kigozi F, et al. Scaling up integrated primary mental health in six low- and middle-income countries: obstacles, synergies and implications for systems reform. BJPsych Open 2019;5:e69.

25 Ahuja S, Hanlon C, Chisholm D, et al. Experience of implementing new mental health indicators within information systems in six lowand middle-income countries. BJPsych Open 2019;5:e71-e.

26 Seward N, Hanlon C, Abdulahi A. Health system strengthening in four sub Saharan African countries (ASSET) to achieve highquality, evidence-informed surgical, maternal and newborn, and primary care: protocol for pre-implementation phase studies. medRxiv 2021.

27 Seward N, Murdoch J, Hanlon C, et al. Implementation science protocol for a participatory, theory-informed implementation research programme in the context of health system strengthening in sub-Saharan Africa (ASSET-ImplementER). BMJ Open 2021:11:e048742.

28 Prost A, Colbourn T, Seward N, et al. Women's groups practising participatory learning and action to improve maternal and newborn health in low-resource settings: a systematic review and metaanalysis. Lancet 2013;381:1736-46.

29 Seward N, Neuman M, Colbourn T, et al. Effects of women's groups practising participatory learning and action on preventive and care-seeking behaviours to reduce neonatal mortality: a metaanalysis of cluster-randomised trials. PLoS Med 2017;14:e1002467.

30 Taylor Salisbury T, Atmore KH, Nhambongo I, et al. Integrating human-centred design into the development of an intervention to improve the mental wellbeing of young women in the perinatal period: the catalyst project. BMC Pregnancy Childbirth 2021;21:183.

31 Esponda GM, Hartman S, Qureshi O, et al. Barriers and facilitators of mental health programmes in primary care in low-income and middle-income countries. Lancet Psychiatry 2020;7:78-92.

32 Ridde V, Pérez D, Robert E. Using implementation science theories and frameworks in global health. BMJ Glob Health 2020;5:e002269.

33 Ghaffar A, Langlois EV, Rasanathan K, et al. Strengthening health systems through embedded research. Bull World Health Organ 2017;95:87.

34 Roberts SLE, Healey A, Sevdalis N. Use of health economic evaluation in the implementation and improvement science fields-a systematic literature review. Implement Sci 2019;14:72.

35 Nilsen P. Making sense of implementation theories, models and frameworks. Implement Sci 2015;10:53.

36 Damschroder LJ. Clarity out of chaos: use of theory in implementation research. Psychiatry Res 2020;283:112461.

37 Powell BJ, Waltz TJ, Chinman MJ, Thomas W, Matthew C, et al. A refined compilation of implementation strategies: results from the expert recommendations for implementing change (ERIC) project. Implementation Sci 2015;10:21.

38 Pantoja T, Opiyo N, Lewin S, et al. Implementation strategies for health systems in low-income countries: an overview of systematic reviews. Cochrane Database Syst Rev 2017;9:CD011086-CD.

39 Effective Practice and Organisation of Care (EPOC). The EPOC taxonomy of health systems interventions. EPOC resources for review authors. Oslo: Norwegian Knowledge Centre for the Health Services, 2016.

40 Proctor E, Silmere H, Raghavan R, et al. Outcomes for implementation research: conceptual distinctions, measurement challenges, and research agenda. Adm Policy Ment Health 2011;38:65-76.

41 Glasgow RE, McKay HG, Piette JD. The RE-AIM framework for evaluating interventions: what can it tell us about approaches to chronic illness management? Patient Educ Couns 2001;44:119-27.

42 Pawson R, Tilley N. Realistic evaluation. London: Sage, 1997.

43 Marchal B, Dedzo M, Kegels G. A realist evaluation of the management of a well-performing regional hospital in Ghana. BMC Health Serv Res 2010;10:24.

44 Mukumbang FC, van Wyk B, Van Belle S, et al. Unravelling how and why the antiretroviral adherence Club intervention works (or not) in a public health facility: a realist explanatory theory-building case study. PLoS One 2019;14:e0210565.

45 Westhorp G. Realist impact evaluation: an introduction. London: Overseas Development Institute, 2014.

46 Rycroft-Malone J, Harvey G, Kitson A, et al. Getting evidence into practice: ingredients for change. Nurs Stand 2002;16:38-43.

47 Dalkin SM, Greenhalgh J, Jones D, et al. What's in a mechanism? Development of a key concept in realist evaluation. Implement Sci 2015;10:49

48 Wand T, White K, Patching J. Applying a realist(ic) framework to the evaluation of a new model of emergency department based mental health nursing practice. Nurs Inq 2010;17:231-9.

49 Dossou J-P, De Brouwere V, Van Belle S, et al. Opening the 'implementation black-box' of the user fee exemption policy for caesarean section in Benin: a realist evaluation. Health Policy Plan 2020;35:153-66.

50 Baum F, MacDougall C, Smith D. Participatory action research. $J$ Epidemiol Community Health 2006;60:854-7.

51 Macaulay AC, Commanda LE, Freeman WL, et al. Participatory research maximises community and lay involvement. BMJ 1999;319:774-8.

52 Green LW, George MA, Daniel M. Study of participatory research in health promotion. Ottawa: Royal Society of Canada. Guidelines for Participatory Research in Health 1994.

53 Brown L, Tandon R. Ideology and political economy in inquiry: action research and participatory research. The Journal of Applied Behavioral Science 1983;19:277-94. 
54 Thiollent M. Action research and participatory research: an overview. International Journal of Action Research 2011;7.

55 Israel BA, Schulz AJ, Parker EA, et al. Review of community-based research: assessing partnership approaches to improve public health. Annu Rev Public Health 1998;19:173-202.

56 Coghlan D B-MM. The SAGE encyclopedia of action research, 2014.

57 Bazzano AN, Martin J, Hicks E, et al. Human-centred design in global health: a scoping review of applications and contexts. PLoS One 2017; 12:e0186744.

58 Weiss C. Nothing as Practical as Good Theory: Exploring Theorybased Evaluation for Comprehensive Community Initiatives for Children and Families. In: JP C, ed. New approaches to evaluating community initiatives: concepts, methods, and contexts. Washington, DC: Aspen Institute, 1995.

59 Kislov R, Pope C, Martin GP, et al. Harnessing the power of theorising in implementation science. Implement Sci 2019;14:103.

60 De Silva MJ, Breuer E, Lee L, et al. Theory of change: a theorydriven approach to enhance the medical Research Council's framework for complex interventions. Trials 2014;15:267.

61 Smith JD, Li DH, Rafferty MR. The implementation research logic model: a method for planning, executing, reporting, and synthesizing implementation projects. Implement Sci 2020;15:84.

62 Anderson A. A community builder's approach to theory of change: a practical guide to theory development. New York: The Aspen Institute, 2004

63 Boulding H, Kamenetzky A, Ghiga I, et al. Mechanisms and pathways to impact in public health research: a preliminary analysis of research funded by the National Institute for health research (NIHR). BMC Med Res Methodol 2020;20:34

64 Vindrola-Padros C, Pape T, Utley M. The role of embedded research in quality improvement: a narrative review. BMJ Quality \& Safety 2017;26:70-80.

65 Heaton J, Day J, Britten N. Collaborative research and the coproduction of knowledge for practice: an illustrative case study. Implement Sci 2016;11:20.

66 Greenhalgh T, Fahy N. Research impact in the community-based health sciences: an analysis of 162 case studies from the 2014 UK research excellence framework. BMC Med 2015;13:232.

67 Penfield T, Baker MJ, Scoble R, et al. Assessment, evaluations, and definitions of research impact: a review. Res Eval 2014;23:21-32.

68 Spaapen J, van Drooge L. Introducing 'productive interactions' in social impact assessment. Res Eval 2011;20:211-8.

69 Oliver K, Cairney P. The dos and don'ts of influencing policy: a systematic review of advice to academics. Palgrave Commun 2019;5:21.

70 Oliver K, Innvar S, Lorenc T, et al. A systematic review of barriers to and facilitators of the use of evidence by policymakers. BMC Health Serv Res 2014;14:2.

71 Hinrichs-Krapels S, Bailey J, Boulding H, et al. Using policy Labs as a process to bring evidence closer to public policymaking: a guide to one approach. Palgrave Commun 2020;6:101.

72 Nelson E. Community engagement and involvement for NIHR research proposals. London: National Institute of Health Research, and Institute of Development Studies, 2019.

73 Kola L, Kohrt BA, Hanlon C, et al. COVID-19 mental health impact and responses in low-income and middle-income countries: reimagining global mental health. Lancet Psychiatry 2021;8:535-50.

74 Yapa HM, Bärnighausen T. Implementation science in resourcepoor countries and communities. Implement Sci 2018;13:154.

75 Craig P, Di Ruggiero E, Chapter FKL. 3, Taking account of context in the population health intervention research process. Canadian Institutes of Health Research (CIHR) - National Institute for Health Research (NIHR. Southampton (UK: NIHR Journals Libary, 2018.

76 Seward N, Hanlon C, Murdoch J. Contextual equipoise: a novel concept to inform ethical implications for implementation research in low-income and middle-income countries. BMJ Global Health 2020;5:e003456.

77 Nevo I, Slonim-Nevo V. The myth of evidence-based practice: towards evidence-informed practice. Br J Soc Work 2011;41:1176-97.

78 Robins CS, Ware NC, dosReis S, et al. Dialogues on mixedmethods and mental health services research: Anticipating challenges, building solutions. Psychiatr Serv 2008;59:727-31.

79 Kruk ME, Yamey G, Angell SY, et al. Transforming global health by improving the science of scale-up. PLoS Biol 2016;14:e1002360.

80 Bennett S, Mahmood SS, Edward A, et al. Strengthening scaling up through learning from implementation: comparing experiences from Afghanistan, Bangladesh and Uganda. Health Res Policy Syst 2017;15:108.
81 De Savigny D, Adam T. Systems thinking for health systems strengthening. alliance for health policy and systems research. WHO, 2009.

82 Gopichandran V, Luyckx VA, Biller-Andorno N, et al. Developing the ethics of implementation research in health. Implement Sci 2016;11:161.

83 Davidoff F, Dixon-Woods M, Leviton L, et al. Demystifying theory and its use in improvement. BMJ Qual Saf 2015;24:228-38.

84 Merton RK. On sociological theories of the middle range. In: On theoretical sociology. New York: Free Press, 1948: 39-72.

85 Hull L, Goulding L, Khadjesari Z, et al. Designing high-quality implementation research: development, application, feasibility and preliminary evaluation of the implementation science research development (ImpRes) tool and guide. Implement Sci 2019;14:80.

86 World Health Organization. Everybody business: strengthening health systems to improve health outcomes: WHO's framework for action. Geneva: WHO, 2007.

87 Rogers PJ. Using programme theory to evaluate complicated and complex aspects of interventions. Evaluation 2008;14:29-48.

88 Curran GM, Bauer M, Mittman B, et al. Effectivenessimplementation hybrid designs: combining elements of clinica effectiveness and implementation research to enhance public health impact. Med Care 2012;50:217-26.

89 Cotterill S, Knowles S, Martindale A-M, et al. Getting messier with TIDieR: embracing context and complexity in intervention reporting. BMC Med Res Methodol 2018;18:12.

90 Hoffmann TC, Glasziou PP, Boutron I, et al. Better reporting of interventions: template for intervention description and replication (TIDieR) checklist and guide. BMJ 2014;348:g1687.

91 Damschroder LJ, Aron DC, Keith RE, et al. Fostering implementation of health services research findings into practice: a consolidated framework for advancing implementation science. Implement Sci 2009;4:50.

92 White MC, Randall K, Capo-Chichi NFE, et al. Implementation and evaluation of nationwide scale-up of the surgical safety checklist. Br J Surg 2019;106:e91-102.

93 Atkins L, Francis J, Islam R, et al. A guide to using the theoretical domains framework of behaviour change to investigate implementation problems. Implement Sci 2017;12:77.

94 Grol R, Grimshaw J. From best evidence to best practice: effective implementation of change in patients' care. Lancet 2003;362:1225-30.

95 Adamu AA, Uthman OA, Gadanya MA, et al. Using the theoretical domains framework to explore reasons for missed opportunities for vaccination among children in Kano, Nigeria: a qualitative study in the pre-implementation phase of a collaborative quality improvement project. Expert Rev Vaccines 2019;18:847-57.

96 Chibanda D, Weiss HA, Verhey R, et al. Effect of a primary care-based psychological intervention on symptoms of common mental disorders in Zimbabwe: a randomized clinical trial. JAMA 2016;316:2618-26.

97 Lester RT, Ritvo P, Mills EJ, et al. Effects of a mobile phone short message service on antiretroviral treatment adherence in Kenya (WelTel Kenya1): a randomised trial. Lancet 2010;376:1838-45.

98 Vousden N, Lawley E, Nathan HL, et al. Effect of a novel vital sign device on maternal mortality and morbidity in low-resource settings: a pragmatic, stepped-wedge, cluster-randomised controlled trial. Lancet Glob Health 2019;7:e347-56.

99 Brandt L, Hidalgo L D-C, et al. Use of smartphone application to treat comorbidity depression with hypertension or diabetes II: a qualitative study about user perception in Peru 2018.

100 Hanlon C, Alem A, Medhin G, et al. Task sharing for the care of severe mental disorders in a low-income country (TaSCS): study protocol for a randomised, controlled, non-inferiority trial. Trials 2016;17:76.

101 Murdoch J, Curran R, Bachmann M, et al. Strengthening the quality of paediatric primary care: protocol for the process evaluation of a health systems intervention in South Africa. BMJ Glob Health 2018;3:e000945.

102 Murdoch J, Curran R, Cornick R, Picken S, et al. Addressing the quality and scope of paediatric primary care in South Africa: evaluating contextual impacts of the introduction of the practical approach to care kit for children (pack child). BMC Health Serv Res 2020;20.

103 Freire P. Pedagogy of the Oppressed. New York: Herder and Herder, 1972.

104 Atchison CJ, Mulhern E, Kapiga S, et al. Evaluating the impact of an intervention to increase uptake of modern contraceptives among adolescent girls (15-19 years) in Nigeria, Ethiopia and Tanzania: the adolescents 360 quasi-experimental study protocol. BMJ Open 2018;8:e021834. 
105 MacFarlane EK, Shakya R, Berry HL, et al. Implications of participatory methods to address mental health needs associated with climate change: 'photovoice' in Nepal. BJPsych Int 2015;12:33-5.
106 Chisholm D, Burman-Roy S, Fekadu A, et al. Estimating the cost of implementing district mental healthcare plans in five lowand middle-income countries: the prime study. Br J Psychiatry 2016;208 Suppl 56:s71-8. 